Revista

Actualidades Investigativas

en Educación

\title{
La libertad de cátedra y la universidad que innova
}

Academic freedom and the innovative university

\author{
Volumen 20, Número 1 \\ Enero - Abril \\ pp. 1-21
}

\section{Roy Campos Retana}

\section{Citar este documento según modelo APA}




\title{
La libertad de cátedra y la universidad que innova
}

\author{
Academic freedom and the innovative university
}

\section{Roy Campos Retana ${ }^{1}$}

\begin{abstract}
Resumen: Este ensayo elabora una narrativa teórica sobre las implicaciones de la libertad de cátedra en los procesos de innovación educativa dentro de las universidades. Para ello, hace un breve recorrido por la historia de la libertad. Concretamente, aborda la evolución de la libertad de cátedra como un derecho de las Instituciones de Educación Superior para protegerse de la imposición de ideologías externas, principalmente las gubernamentales. Luego, explora las novedosas transformaciones educativas basadas en la tecnología, las cuales tuvieron efecto en la docencia, tanto dentro como fuera de los salones de clases, debido especialmente a las plataformas virtuales y a la educación híbrida. Se encontró que los nuevos paradigmas educativos se relacionan con la libertad de cátedra, pero de manera relativa, y según la legislación de cada país. Para explicarlo, se revisaron tres contextos geográficos distintos, a saber: Alemania, España y Costa Rica, donde la aplicación de la libertad de cátedra es variada. Al final del ensayo, se concluye que la libertad de cátedra es un principio que puede impedir, tanto a la universidad como al gobierno, conculcar la autoridad del profesorado universitario; no obstante, su efectividad es relativa.
\end{abstract}

Palabras clave: innovación educativa, educación superior, libertad de cátedra

Abstract. This scientific essay addresses the implications of academic freedom and the innovative educative process within universities. Specifically, this article focuses on how academic freedom evolved as a right that higher education institutions use to protect themselves against external ideologies, mainly to avoid governmental influence. It makes a brief approach to freedom history. Later, it explores novel educative transformations based on technology, specifically those impacting teaching like virtual platforms and blended learning. We found that the new educative paradigms are nearly connected to academic freedom, depending on each country's legislation. Drawing from the experiences of Germany, Spain, and Costa Rica, this essay explores how academic freedom can resist government and university to overcome the authority of the professor. Nevertheless, we conclude considering how academic freedom is a relatively capable medium to achieve autonomy.

Keywords: educative innovation, higher education, academic freedom

1 Profesor de la Universidad de Costa Rica, en la Escuela de Administración de Negocios, Costa Rica. Master en Gobierno y Cultura de las Organizaciones, Universidad de Navarra; donde cursa sus estudios doctorales. ORCID https://orcid.org/0000-0001$\underline{7519-9219}$

Dirección electrónica: roy.camposretana@ucr.ac.cr

Ensayo recibido: 16 de junio, 2019

Enviado a corrección: 10 de setiembre, 2019

Aprobado: 18 de noviembre, 2019

Los contenidos de este artículo están bajo una licencia Creative Commons 


\section{Introducción}

La libertad de cátedra tiene sus orígenes en la libertad misma, por lo que comprender su papel en la institución universitaria amerita entender el uso de la libertad en la historia del pensamiento humano. Desde la Edad Media hasta la Posmodernidad, cuando emerge la sociedad de la información y del conocimiento, la educación superior se vio enfrentada a numerosos desafíos que la obligaron a innovar. La creación de un nuevo paradigma universitario forzó al profesorado a buscar algo más que la verdad, le situó frente a modelos de educación híbridos y le posicionó en una difícil decisión: enseñar la verdad o generar riqueza.

No ha sido fácil para la institución universitaria, pública o privada, adaptarse a las diferentes épocas, y atender intereses, ya sea para buscar la universalidad de los saberes o bien para responder a una lógica de mercado. Sin embargo, el atributo de la antigüedad no basta para comprender si la innovación educativa es suficiente para enfrentar los nuevos retos que afectan el ejercicio de la libertad de cátedra. En cambio, la distinción entre universidades virtuales y tradicionales sí ayuda a comprender atributos tales como: el perfil del profesorado, la magnitud de la infraestructura institucional, la cantidad de recursos, las herramientas tecnológicas, entre otros.

La libertad de cátedra es un derecho que les permite a las universidades dotarse de una autonomía especial, a ellas y a su claustro, pero no necesariamente las protege de las tendencias para constituir un nuevo paradigma educativo. Su aplicación puede cambiar según la legislación de cada país y también de cada institución. Para ejemplificar su alcance, se analizarán tres contextos geográficos determinados, Alemania, España y Costa Rica. El primero, por ser el de más antigüedad en el ejercicio de este derecho; el segundo, por tener importante influencia en Iberoamérica; y el tercero, por referirse al contexto centroamericano.

\section{Desarrollo del tema}

\subsection{Breve historia de la universidad como generadora de conocimiento}

En la baja Edad Media, eran los miembros del clero quienes conservaban la promoción del conocimiento, pero poco a poco se conforman instituciones en las que se incorporan un amplio rango de saberes para dar origen a uno de sus rasgos fundacionales: la universalidad. La Europa medieval era esencialmente católica, procuraba hacer uso de la razón para encontrar el fin de las cosas (telos), al tiempo que contaba con la ayuda de Dios (la gracia) como complemento del ejercicio de la virtud. En ese momento de la historia, la 
razón y la fe confluían en la concepción de la naturaleza humana que, pese a estar herida por el pecado, aspiraba a un bien superior.

Según Madrid (2013, p. 359), los orígenes de la universidad datan desde el siglo XI y se prolongaron hasta los últimos siglos de la Edad Media en diversos países de Europa. La universidad buscaba el crecimiento del espíritu y su aspiración trascendente procuraba encontrar de la verdad. Hacia el final de la Edad Media (siglo XV), el auge del Humanismo se apoyó, entre otras cosas, en las lenguas vernáculas (el latín dejará de ser la lengua franca) y en la imprenta. Aquella libertad del alma atendía a conocer la verdad y querer el bien mediante el ejercicio de la voluntad y del intelecto, en coherencia con la enseñanza evangélica: "la verdad os hará libres".

En el Renacimiento (siglo XV-XVI), el arte, los escritos clásicos y la historia estaban custodiados en muchas ocasiones por la Iglesia Católica. No obstante, poco a poco el humanismo cobró un carácter más secular y se fue separando de sus fundamentos cristianos. La búsqueda de la verdad comenzó a estar marcada por el uso de la razón y la experimentación científica. La religión pasó a un segundo plano y, en algunos casos, se la negó, desembocando así en la revolución científica y la llustración.

Durante los siglos XVII-XVIII se empezó a renegar de la religión revelada, o al menos pasó a un segundo plano, en parte porque la razón se colocó por encima de todo y, en parte, por la pugna entre católicos y protestantes. La sola fide anuló o, al menos, redujo la posibilidad moral, porque se ciñó en el ser humano un tipo de determinismo existencialista: bastaba confiar en Dios, sin importar mucho la coherencia de vida. Es entonces cuando el progreso económico y técnico empezaron a identificarse con el desarrollo, porque el crecimiento estaba en función de avanzar, muchas veces sin sentido, o al menos con un propósito dominado por intereses menos trascendentes.

El Cristianismo, que veía en la Encarnación del Verbo el culmen de la historia, se enfrentó a una nueva concepción del ser humano y del mundo, dando paso a una naturaleza más confiada de sí misma. Desde el final de la Edad Media y hasta el inicio de la llustración, la razón cobró un papel protagónico, antropocéntrico, y el progreso se empezó a mirar como algo bueno en sí mismo. En esta transición, se sustituyó la libertad moral por la liberación intelectual y la Verdad liberadora se redujo a una fruición intelectual.

En la Edad Moderna, el acceso al conocimiento movió su centro de gravedad: las fronteras físicas fueron desdibujadas cuando los límites del conocimiento se percibían como ilimitados. Las esferas del poder político, económico y militar abrieron nuevos frentes de 
guerra en campos de batalla que estuvieron delineados por las diversas disciplinas del saber. Esa expansión de la academia no solo se redujo a Europa, sino que se extendió a América. La liberación de la ignorancia permitió al ser humano construir armas poderosas, en las que el capital económico tuvo que estar acompañado del progreso científico. Aparecieron las universidades privadas, cuyo modelo de negocios no solo era una declaración de independencia, sino, en ocasiones, de poder.

El alcance de las ciencias en el mundo fue cada vez mayor: al mismo tiempo que los Estados se hacían de fuerzas armadas y con la carrera armamentista avanzaba el conocimiento, también fundaron universidades para custodiar su patrimonio intelectual. Las nuevas corrientes de pensamiento empezaron a forjar la identidad de la historia: el Antropocentrismo (siglos XV-XVI), el Naturalismo (siglos XVI-XVII) y el Racionalismo (siglos XVII-XVIII) dieron origen al Liberalismo. El capitalismo escocés del Adam Smith se estableció como un sistema de organización societaria y moral, el cual se movió en función del selfinterest. Aparecieron sistemas totalitaristas prometiendo una eventual reivindicación social; sin embargo, solo consiguieron frustrar a la humanidad. Si la religión dotaba al ser humano de esperanza, la ciencia lo inundaría de fe, pero una fe en sí misma: "seréis como Dioses". El protagonismo del individuo anuló la presencia de Dios en muchas dimensiones de su existencia.

Posteriormente, la liberación de restricciones se convirtió en un totalitarismo per se: el libertinaje. La libertad de esta época ya no será una libertad "para", sino una libertad "de": la ciencia podrá explicar el funcionamiento de un arma letal, pero nunca el sentido de la guerra. El desencanto de la humanidad se desplegó en caos, en revoluciones intelectuales y sociales porque la primera y segunda guerras mundiales, lejos de ser liberadoras, solo lograron esclavizar la dignidad de las personas. Las universidades se convirtieron en los espacios donde se libraron estas batallas y, para lograrlo, se empezó a defender su independencia. Tal será el caso de la crisis de 1968, en la cual el ser humano le reclamaría al tiempo la paz, ese valor que era suyo por naturaleza, pero que le había sido arrebatado con violencia.

Mientras la cátedra defendía su libertad ideológica, la investigación se prefiguraba como instancia de autoridad. El profesorado se uniría en un frente común: dotar a la universidad de autonomía. Se protegió la pluralidad de ideas y la diversidad de pareceres, al tiempo que se desvinculó la recepción de fondos estatales de líneas de pensamiento e imposición política porque, como afirmará Foucault (1992) "el saber académico, tal y como 
está distribuido en el sistema de enseñanza, implica evidentemente una conformidad política" (Foucault, 1992, p. 32).

\subsection{Proposición: La crisis de la universidad}

En Madrid, a mediados del siglo XX, se vislumbraba una universidad que entraría en crisis: sería vista como una empresa, mientras que el alumnado sería visto como el cliente. Las cátedras adquirirán los nombres de las personas benefactoras y las líneas de investigación, los de los mercados. Así lo explica Madrid (2013):

La misión de la universidad ya no es la verdad trascendente, como en la clásica, ni la verdad inmanente, como en la moderna. Tampoco es el servicio al Estado o a la comunidad a través de la formación de profesionales de excelencia. El objetivo de la nueva universidad es ser expresión de la democracia a través de la afirmación de lo individual sin jerarquía (como la antigua relación de profesor y alumno). Esto trae como consecuencia la concepción de la universidad, más que como una institución con finalidad propia, como una simple estrategia de poder. (p. 370)

Debido a ello, la educación basada en competencias, así como los procesos de acreditación y los parámetros fijados por el Estado, constituyeron un mecanismo de control y unificación que, por un lado, garantizaron un mínimo de calidad en los procesos de enseñanza, pero, por otro, obligaron a dar soluciones carentes de creatividad y personalización. Ante estas desviaciones, la institución universitaria ciertamente corría el riesgo de perder su identidad. En efecto, el cambio de paradigma que enfrentaron las universidades tradicionales para competir contra la multitud de actores que buscaban el lucro, muchos de ellos incapaces de hacerlo compatible con la búsqueda de la verdad, obligó a las instituciones académicas a una competencia sobredimensionada, en la que se limitaron las posibilidades de creatividad del profesorado y del estudiantado, en apariencia, ampliadas con propuestas tecnológicas de moda, pero ausentes de un sentido didáctico. En lo relativo a esta transformación del modelo educativo, Llano (2012) ejemplifica lo siguiente:

La innovación exige, sobre todo, anticiparse. Lo cual no se identifica en modo alguno con la programación. La programación - que hoy parece obsesionar a muchos - es la proyección del pasado en el futuro. La anticipación, en cambio, es el descubrimiento de un porvenir que está llamando a nuestras puertas, pero que no sabemos a ciencia cierta por dónde y cómo aparecerá. El futuro no se puede diseñar de antemano: hay 
que vislumbrarlo y, en cierto modo, inventarlo. No queremos reducir la universidad a sus registros, actas, documentos, evaluaciones, presupuestos, o comunicaciones internas y externas. (p. 96)

A causa del rompimiento de este paradigma educativo, la educación superior se vería desafiada. Más allá de buscar la verdad, se vería obligada a competir en una sociedad de información, caracterizada por la gestión de reconocimientos que la certificaran como portadora del saber. En consecuencia, la universidad tendría que someterse irremediablemente a tratados, acreditaciones y rankings internacionales. Solo así sería capaz de posicionarse socialmente. De hecho, el prestigio institucional ya no sería un reconocimiento social, sino una marca, un atestado dado, e incluso, impuesto. No obstante, los outputs y outcomes de la educación no siempre han sido posibles de cuantificar, porque hay realidades cualitativas que no son susceptibles de mesura, especialmente aquellas que corresponden al desarrollo del espíritu. A menos que algo sucediera, la universidad tendría que transformar su modelo pedagógico para continuar siendo sostenible en el tiempo.

Si la universidad fue capaz de adaptarse a los diversos momentos de la historia, sería razonable pensar que aquella nueva época no sería la excepción. La crisis de la educación superior no era la pérdida de identidad, sino la ausencia de madurez para vincular su oferta académica a las demandas de la sociedad, al tiempo que estaba llamada a custodiar aquello que le correspondía por naturaleza: promover la universalidad de los saberes. Por tanto, la docencia, la investigación y la vinculación con la sociedad, funciones sustantivas de la universidad, tendrían que evolucionar. Esta transformación le permitiría, en muchos casos, alcanzar una sostenibilidad económica y autonomía, pero seguiría latente el riesgo de desdibujar su esencia.

Los riesgos los detonan las crisis provocadas por cambios bruscos e importantes que sufren las personas y las instituciones. Estos riesgos provocan momentos de inestabilidad y ponen en peligro lo que se aprecia y valora. El problema de la innovación educativa constituía una crisis para la universidad, en parte porque la tecnología y las necesidades del mercado se habían visto como fines y no como medios. Ante todo, la incursión de los paradigmas educativos emergentes debía venir precedida de procesos reflexivos, de tal manera que fuera posible mitigar los efectos negativos de lo moderno. Adelantarse al futuro podía constituir una ambición noble, pero si el futuro es por definición lo desconocido, lo más oportuno sería comprender a profundidad el comportamiento humano, las ventajas y 
desventajas de lo que ofrecía la tecnología para enfrentar con prudencia las ventajas y desventajas de la innovación.

La innovación ha estado impulsada por la capacidad de ver conexiones, detectar oportunidades y sacar provecho de ellas. Al mismo tiempo, la innovación ha procurado crear nuevas posibilidades mediante la combinación de diferentes conjuntos de conocimiento (Tidd, Bessant, y Pavitt, 2005, p. 15). En consecuencia, la innovación ha cambiado el centro de gravedad del aprendizaje, porque ha permitido que la oportunidad de conectar saberes desde un espacio virtual, avance al ritmo que se impone el estudiantado y ya no a la velocidad del profesorado. A esto se añade que la sociedad de la información permite aprender, en ocasiones, a través del Internet y plataformas tecnológicas de gran calidad, sin mediación docente, hasta prescindir de la interacción física entre individuos. La variedad de saberes a los cuales se puede acceder ya no está marcada por una malla curricular previamente diseñada, sino por las inquietudes del estudiantado y su libertad de navegar, de buscar en la Web y de comprometerse consigo mismo. Desde entonces, las relaciones humanas y el salón de clases han ido ampliándose e incluso han sido reemplazados por la mediatización y la tecnología. Esta realidad encontró sus raíces a finales del siglo XX:

Continúan existiendo los grandes mecanismos secretos mediante los cuales una sociedad transmite su saber y se perpetúa a sí misma bajo una apariencia de saber; estos mecanismos están todavía en pie: periódicos, televisión, escuelas técnicas, y los Institutos todavía más que la Universidad. (Foucault, 1992, p. 37)

La libertad de enseñar y debatir sin verse limitado por doctrinas impuestas o intereses particulares no es ajena a esta corriente de innovación en la educación superior. Eventualmente, pareciera que los nuevos paradigmas educativos podrían afectar la capacidad del profesorado para desplegar su saber. Las tendencias en la educación superior podrían suponer una limitación para el desarrollo de las capacidades propias del estudiantado crítico y maduro. Visto desde esta perspectiva, la estandarización del conocimiento, así como la tecnología en sí misma serían amenazas potenciales a la labor del profesorado, cuya responsabilidad en los procesos de mediación pedagógica es sustancial. Ciertamente, las nuevas tecnologías desarrollan numerosas habilidades y destrezas, y también las competencias que promueven la educación híbrida y virtual. Debido a todo lo expuesto hasta el momento, este ensayo pretende responder a la pregunta ¿Puede la innovación en la educación superior atentar contra la libertad de cátedra? Para ello se 
revisarán los desafíos de una universidad que innova, así como el desempeño de la libertad de cátedra en contextos geográficos distintos.

\subsection{Argumentos para la discusión}

\subsubsection{Los desafíos para la universidad que innova}

Eyring y Christensen (2011) exploran los desafíos a los que se enfrentan las universidades tradicionales ante las nuevas ofertas tecnológicas de los estudios en línea. Las instituciones clásicas contaban con dos activos principales: el campus físico, construido por décadas mediante un gasto enorme, y el profesorado. Todo esto poseía un costo muy elevado, el cual solía ser asumido por el Estado, los sponsors, las investigaciones y el estudiantado. Es por ello que las universidades, al igual que muchas organizaciones, procuraban no solo sobrevivir, sino desarrollarse y mejorar en escala, alcance y prestigio. La universidad, para crecer, debía expandir su campus, lo cual implicaba inversiones millonarias en activos, lo mismo que en el desarrollo de un profesorado de prestigio.

De esta manera la extensión de una universidad se caracterizaba por la calidad de su profesorado, así como por la excelencia de sus instalaciones. Contrario a lo que sucederá en la sociedad de la información, el posicionamiento de una universidad a nivel mundial estaba dado por factores físicamente tangibles, mientras que con el paso de los años, ese prestigio empezaría a forjarse a base de elementos más tecnológicos y virtuales. La barrera entre lo real y lo virtual empezaría a desdibujarse a tal punto que las instituciones de educación superior de mayor renombre empezarían a migrar hacia un nuevo paradigma educativo antes no previsto.

Adicionalmente, Eyring y Christensen (2011) no distinguen entre universidades públicas y privadas, sino entre universidades tradicionales y nuevos actores. En su artículo Changing the DNA of Higher Education, en la categoría de universidades tradicionales, encajan las universidades públicas y privadas que gozan de cierta trayectoria y prestigio; mientras que con el término nuevos actores parecen referirse a las universidades virtuales, con plataforma tecnológica y que no requieren una acreditación formal para operar. Asimismo, sugieren que en la nueva era del conocimiento, a las universidades tradicionales no les resulta fácil vincularse a las demandas de la sociedad, donde actores particulares e institucionales empiezan a integrar la tecnología en sus clases y, con ella, reconfigurar el nuevo paradigma educativo que distinguirá al siglo XXI. Esto les permitirá a las nuevas generaciones gozar de 
la posibilidad de incurrir en nuevas titulaciones en línea y de accesibilidad desde sus casas con un profesorado desconocido o reconocido.

A esta fuerza positiva, Christensen, Johnson, y Horn la llamarán innovación disruptiva, "el proceso por el cual una innovación transforma un mercado cuyos servicios o productos son complicados y caros, en uno donde la simplicidad, conveniencia, accesibilidad y asequibilidad caracterice la industria" (2008, p. 11). Ahora bien, simultáneo al incremento del número de estudiantes de programas en línea, los costos de las universidades tradicionales aumentaron. Para este tipo de instituciones, el prestigio constituía una ventaja natural y el precio, un criterio de ingreso - aunque en muchos casos siguió siendo inaccesible para bastantes personas - Frente a ello, la universidad tradicional tendría que transformarse, ya no físicamente, sino internamente, a nivel de docencia y plataformas de enseñanza, porque sería su profesorado quienes debían reinventarse, y de este modo protagonizar el nuevo modelo pedagógico dentro de las instituciones de educación superior clásicas y reconocidas.

Entonces, aparecerían dos extremos: por un lado, los fanáticos del cambio, que apostarían por la disrupción y la obsolescencia de las universidades tradicionales; por otro, los detractores de ese cambio inminente y firmes defensores del modelo conservador, del antiguo paradigma educativo, basado en las clases magistrales, la presencialidad y las aulas clásicas propias del aprendizaje pasivo. Estos nuevos oferentes del siglo XX se convirtieron paulatinamente en universidades, muchas de ellas sin una constitución formal dentro de la normativa de un país. A pesar de ello, generaron efectos positivos, tales como llevar la educación superior a las masas y contribuir a la difusión del conocimiento. Fue así como las acreditaciones vendrían a conformar una medida de normalización de la calidad educativa, principalmente en sociedades saturadas de oferentes. De este modo, el Estado aparecería como ente regulador y tendría que pronunciarse como garante de la seguridad.

Históricamente, la educación superior había evitado neutralizar la participación de estos nuevos actores, pues en el pasado el prestigio de una universidad era sinónimo de calidad, un atributo difícil de medir, especialmente en el sector educativo. Se podría suponer que la calidad era susceptible de cuantificarse externamente en términos de niveles de publicaciones (artículos y libros, por ejemplo), tipo de profesorado (equipo investigador, grados académicos), entre otros. No obstante, ocurría que los potenciales estudiantes no siempre utilizaban este tipo de indicadores como un factor decisivo para escoger en qué institución matricularse. 
Llegados a este punto, conviene hacer explícito el problema al que se enfrenta la universidad actual, en sintonía con los autores citados anteriormente. Se trata de una competencia en la que nuevas personas e instituciones, que poseen un nuevo modelo educativo, claramente sofisticado, están provocando consecuencias negativas en las universidades tradicionales. Sus principales efectos hacen referencia a la estandarización y a la formalización: mientras las universidades tradicionales -con prestigio o no- deben ostentar las mismas acreditaciones para ser reconocidas como válidas por la sociedad, las universidades virtuales no requieren de este tipo de reconocimientos. En cambio, estas universidades en línea sí demandan de conectividad y otros aspectos para su funcionamiento; por ejemplo, en sus diseños instruccionales hay componentes pedagógicos necesarios para el aprendizaje virtual.

Esto permite entender que estos nuevos oferentes, aunque carentes de una infraestructura física, sí requieren de algunos aspectos propios de las universidades tradicionales. Aunque se les cuestiona como universidades, confieren títulos que son incuestionables. El conflicto que se genera obedece a que no hay una instancia de poder que pueda obligarlas a formalizarse, en cambio, existe un grupo importante en la sociedad que sí las reconoce como tales. Reaparece entonces el dilema entre legalidad y legitimidad, con una magnitud y complejidad muy actuales.

Con la intención de comprender las características de ambos modelos, en la Tabla 1 , se compara el avance del modelo tradicional de universidad con respecto al modelo de universidad en línea. Ahora bien, conviene aclarar que limitar la innovación educativa a la universidad en línea, sería caer en un reduccionismo. La innovación es más que la generación de ideas creativas: es la implementación de esas ideas en un nuevo dispositivo o proceso (Schilling, 2016, p. 21). Por ende, resulta obligatorio referirse a la integración de la tecnología en las instituciones de educación superior como el detonante de la transformación educativa. La universidad en línea no es la única forma de innovación, más bien, es una modalidad de estudio que utiliza una plataforma tecnológica, la cual le ofrece la oportunidad de acceso a estudios universitarios a una población que no lo hace presencialmente, ya sea por condiciones del entorno o por motivos propios. Eyring y Christensen (2011) utilizan como referencia la Universidad de Harvard, considerando que es una de las instituciones de educación superior de mayor prestigio en el mundo. 
Tabla 1. Modelos de la universidad tradicional vrs la universidad en línea

\begin{tabular}{|c|c|c|}
\hline $\begin{array}{l}\text { Según la era de } \\
\text { Harvard }\end{array}$ & $\begin{array}{c}\text { Rasgos de la } \\
\text { universidad tradicional }\end{array}$ & $\begin{array}{c}\text { Rasgos de la } \\
\text { universidad en línea }\end{array}$ \\
\hline \multirow{2}{*}{$\begin{array}{l}\text { Harvard College } \\
1636-1707\end{array}$} & Instrucción cara a cara & No \\
\hline & Largos recesos de verano & No \\
\hline \multirow{4}{*}{$\begin{array}{l}\text { Charles W. Eliot } \\
1869-1909\end{array}$} & $\begin{array}{lcc}\text { Intercambio de } & \text { profesorado } & \text { para } \\
\text { programas de grado y pregrado } & \\
\end{array}$ & No \\
\hline & $\begin{array}{l}\text { Especialización comprehensiva, } \\
\text { departamentalización, y autogobierno del } \\
\text { profesorado. }\end{array}$ & No \\
\hline & Fundraising privado & No \\
\hline & Deportes competitivos & No \\
\hline \multirow{2}{*}{$\begin{array}{l}\text { Lawrence Lowell } \\
\text { 1909-1933 }\end{array}$} & $\begin{array}{l}\text { Distribución curricular y concentración } \\
\text { (majors) }\end{array}$ & Ofertas dirigidas \\
\hline & Reconocimientos académicos & No \\
\hline \multirow{3}{*}{$\begin{array}{l}\text { James Conant } \\
\text { 1933-1953 }\end{array}$} & $\begin{array}{l}\text { Régimen académico, con rango } \\
\text { académico y distinciones salariales }\end{array}$ & No \\
\hline & Admisiones selectivas & No \\
\hline & Fondo externo de investigación & No \\
\hline
\end{tabular}

Fuente: Adaptado de Eyring y Christensen (2011, pp. 6-7)

Las universidades empezaron a buscar una mayor implicación con las nuevas plataformas de conocimiento en línea. La disyuntiva natural es cuestionarse cuál era el camino correcto: ¿lo clásico o lo nuevo? Según Eyring y Christensen (2011) lo apropiado sería encontrar un punto intermedio donde se complemente lo mejor de ambos mundos:

La ventaja real de las universidades tradicionales es su capacidad de combinar las experiencias online y cara a cara. La instrucción híbrida ha probado ser más efectiva que cualquiera de los métodos puros. Las universidades tradicionales pueden entregar lo mejor de ambos: bajo costo y aprendizaje en línea, combinado con instrucción periódica en las aulas. Más aún, el aprendizaje cara a cara en la universidad tradicional va más allá del salón de clases: incluye la importancia del aprendizaje informal que viene cuando los estudiantes interactúan uno con otro en actividades sociales y con profesores en investigación. (2011, p. 8)

Una innovación educativa debería enfocarse en mejorar los procesos de aprendizaje del estudiantado, sin que esto suponga perder uno de los rasgos esenciales de la universidad: su humanismo. El trato personal nunca podrá ser perfectamente emulado por un software o un hardware. El uso de la tecnología abre grandes posibilidades, pero su abuso limita las capacidades de aprendices y enseñantes. La docencia tiene un sentido, pero 
restarle humanidad la hace perder su propósito. La creatividad es la semilla de la innovación y la tecnología, uno de sus principales componentes. El hecho de sugerir una combinación sana entre lo clásico y lo nuevo no es garantía de lograr una innovación favorable, porque la justa medida no es fácil de encontrar. ¿Cuáles son los criterios para definir la cantidad de cambios que una persona docente le debe hacer a su trabajo? ¿Qué debe tomar en consideración la institución educativa para decidir lo que le conviene a ella, a su profesorado, pero sobre todo a su estudiantado? Sobre este punto tratará el próximo apartado de este artículo.

\subsection{La libertad de cátedra en contextos geográficos distintos}

El cuestionamiento que se desea responder en esta sección es si la innovación educativa respeta la libertad de cátedra. Para ahondar en esta problemática se utilizarán las definiciones de poder y autoridad planteadas por Herrero (2015):

El reconocimiento del poder se expresa en la sumisión u obediencia no coactiva. Un poder es reconocido como potestad y por tanto se permite su institución, cuando genera obediencia de derecho. D'Ors liga este reconocimiento a un nuevo concepto, el de auctoritas. Siguiendo la experiencia romana, D'Ors define como autoridad un saber personal socialmente reconocido. ( p. 61)

¿La potestad de una universidad que promueve nuevas formas de abordar los contenidos y plataformas tecnológicas conculca la autoridad que le es propia al profesorado, considerado este como una comunidad reconocida dentro de la misma institución académica a la que pertenece? Para ello, se expondrán brevemente algunas concepciones de este derecho, y posteriormente se analizarán sus implicaciones en la innovación educativa.

La libertad de cátedra nació como una exigencia jurídica alemana para evitar la intervención gubernamental en el profesorado que investigaba:

El Bundesverfassungsgericht entiende por libertad de cátedra el derecho que tiene el docente para la libre elección de objeto, forma, método y contenido. Forman parte de la enseñanza la celebración de actividades docentes en el marco de la Universidad (Lehrveranstaltungen), especialmente las lecciones (Vorlesungen), clases prácticas (Übungen), seminarios y coloquios, así como la fijación de contenidos y métodos, junto con las formas de transmisión y expresión de estos conocimientos. La jurisprudencia 
establece como criterio identificativo de la libertad de cátedra que la tarea docente se lleve a cabo de modo independiente y autónomo. (Vidal, 2004, p. 378)

En Alemania también existen referencias de libertad pedagógica, pero solo para referirse al profesorado no universitario. La diferencia estriba en que la libertad de cátedra es reconocida como derecho fundamental, "mientras que la pedagógica es un derecho de los docentes, pero no se encuentra entre los constitucionalmente protegidos como fundamentales" (Vidal, 2004, p. 373). Según Madrid (2013), la libertad de cátedra alemana forma parte de lo que se podría denominar "derechos de primera generación" (p.356), un derecho moderno que procura impedir que instancias civiles e institucionales intervengan en el libre desempeño del personal académico. Así, se explica que en la universidad alemana del siglo XIX fuera tan importante la Lernfreiheit, o libertad de estudio, que incluía la posibilidad de escoger los cursos, incluso en más de una universidad, y la de hacer los exámenes finales en el momento y lugar que se quisiera.

Según González-del-Valle (1981), la libertad de cátedra en España consistía en una manera de proteger a la persona docente contra el abuso del poder del Estado si este pretendía interferir sobre una instancia del saber en la sociedad, la cual debería gozar de una especial autonomía para su sano ejercicio. De hecho, un profesor podía acudir a los tribunales si se le obligaba a enseñar una doctrina específica o si se le impedía expresar sus convicciones científicas:

En 1978, época de la promulgación de la vigente constitución española, la libertad de cátedra tiene cuatro dimensiones bien explícitas: libertad de opinión docente; en segundo lugar, que la Universidad está al servicio de la ciencia y no del Estado; en tercer lugar, que esa autonomía frente al Estado sólo es posible si éste subvenciona económicamente a la Universidad; y por último, que esa libertad de cátedra conlleva que las decisiones en el campo del nombramiento de profesores, de la investigación y de la docencia deben estar tomadas por una mayoría absoluta de profesores cualificados y no por cogestión de éstos junto con estudiantes, aprendices de profesores y personal administrativo de la Universidad. (González-del-Valle, 1981, p. 318)

La libertad de cátedra goza, por un lado, de un contenido negativo que encierra dos dimensiones: primero, la imposibilidad del Estado de imponer ideologías; segundo, la 
capacidad de "elegir, utilizar y aplicar los métodos, procedimientos y tratamientos conducentes a la adquisición, exposición y transmisión de los conocimientos científicos" (Malagón, 2011, p. 430). Por otro lado, se entiende como contenido positivo de esta libertad el que "ampara la libre programación y el desarrollo igualmente libre de la docencia, si bien respetando los planes y programas mínimos establecidos por quienes tienen competencia para ello" (Malagón, 2011, p. 431).

La definición de libertad de cátedra y su legislación irá evolucionando en el ámbito de los derechos de las personas. La libertad de cátedra alcanzará la libertad de expresión, el ejercicio de la profesión, y la separación de las instituciones, hasta impedir, por ejemplo, la injerencia de un poder político sobre una institución de educación superior. Es así como cobró el rol de un derecho fundamental y llegó a entenderse como aquel que "protege la libertad del enseñante, no sólo frente a una actividad de censura por parte de las autoridades del Estado, sino frente a la injerencia del poder político en la institución universitaria" (González-del-Valle, 1981, p. 317).

La cuestión planteada al inicio de este apartado ha sido si la autonomía del profesorado puede ser incautada por las instituciones educativas que deseen establecer procesos de mejora educativa a los cuales no quieran acceder. Dicho lo anterior, se puede concluir que la libertad de cátedra es un derecho que procura la prudente medida entre los principales actores de la educación: el Estado, las instituciones y la ciudadanía. Esta última encarnada principalmente por las universidades y el profesorado, sin exonerarles nunca de la responsabilidad que han asumido. En todas sus dimensiones, se promoverá la libre transmisión del saber, con autonomía y participación, lo que permitirá darle legitimidad al proceso de enseñanza.

La contraparte de esta libertad será la responsabilidad del profesorado, ahora marcada por una obediencia a la institución -universidad-, pero también caracterizada por una autonomía particular, de la cual se deriva un especial poder sobre su estudiantado. Con respecto a la responsabilidad que confiere este derecho, al profesorado se le puede exigir cumplir con los parámetros de organización, programación horaria, sistemas de evaluación, contenidos, e incluso aquellos procedimientos administrativos establecidos en el plan de estudios y los que se han definido institucionalmente. Todo esto, con el objeto de garantizar una efectiva transmisión de conocimientos al estudiantado, según los fines educativos que se han fijado y los recursos que se han asignado. 
A la luz de lo expuesto hasta el momento, puede afirmarse que la libertad de cátedra, al menos en España, no es una herramienta eficaz para que el profesorado se exonere de acatar los lineamientos de innovación que sugiera una institución de educación superior, salvo aquellos casos en los que se le exija dictar doctrinas o ideologías particulares. Más aún, es previsible que estas innovaciones se vuelvan más vinculantes, conforme todos los procesos, personas y actores se vayan alineando a los objetivos corporativos, a fin de cocrear una nueva cultura organizacional.

A diferencia de países como Alemania, la libertad de cátedra en España no es capaz de liberar al profesorado de su responsabilidad para con la universidad. Al menos no lo podrá hacer por derecho, pero sí de hecho. En tales casos, la institución educativa será la que indique hasta qué punto es vinculante su acatamiento. Precisamente dentro de este contexto es donde se le da forma a la innovación educativa: cuando la institución decide establecer procesos que el profesorado debe acatar, ya no irrespetando sus ideologías propias, sino promoviendo positivamente mejoras que el educador tendrá que incorporar como parte de sus estrategias y metodologías didácticas. Esto precisamente es lo que le confiere una auténtica autoridad, porque "un saber es siempre inicialmente personal" (Herrero López, 2015, p. 61).

En el caso de España parece que la autonomía del profesorado no es absoluta, sino relativamente restringida, en cuanto a formas y métodos de aplicación, lo que lleva a suponer que podría ser más fácil exigirle al profesorado apegarse a cambios e innovaciones; en caso contrario, podría traer sanciones o represalias. Por ejemplo, imaginemos el caso de un grupo del profesorado que acatara las directrices sobre ciertas innovaciones, versus otro que grupo de docentes que no las asume. Si la decisión del profesorado que invocó la libertad de cátedra para no acogerse a las innovaciones, fuera en detrimento del aprendizaje del estudiantado, este último tendría la posibilidad de exigirle, bajo el derecho de la misma libertad, que se apegara a las mejoras prescritas por la autoridad académica competente.

Por otro lado, en Costa Rica, el artículo 87 de la Constitución Política establece que "la libertad de cátedra es un principio fundamental de la enseñanza universitaria" (Sistema Costarricense de Información Jurídica, 1949). Además, el artículo 28 de la misma Constitución (Sistema Costarricense de Información Jurídica, 1949) dispone que "nadie puede ser inquietado ni perseguido por la manifestación de sus opiniones ni por acto alguno que no infrinja la ley". Finalmente, el artículo 81 del mismo documento (Sistema Costarricense de Información Jurídica, 1949), expone que "la dirección general de la 
enseñanza oficial corresponde a un consejo superior integrado como señale la ley, presidido por el Ministro del ramo".

Según Gómez (2004, pp. 74-75) hay cuatro momentos históricos relevantes relacionados con el origen de la libertad de cátedra en Costa Rica, y uno de ellos posee especial relación con la cuestión religiosa. En primer lugar, la fundación de la Universidad de Santo Tomás en el año 1843 y derogada en 1888; en segundo lugar, la declaración de esta institución como pontificia universidad en 1853, por el Papa Pío IX; en tercer lugar, la creación de la Universidad de Costa Rica, mediante Ley № 362 del 26 de agosto de 1940; y en cuarto lugar, la promulgación de la Constitución Política de la República en 1949.

Con respecto a la Universidad de Santo Tomás, primer centro de educación superior, cabe la posibilidad de pensar que, en una institución confesionalmente católica, la libertad de cátedra sea más susceptible de ser influida. No obstante, ese argumento podría ser defendido a nivel teórico, pero refutado a nivel práctico, por lo indicado antes en los artículos 28 y 81 de la Carta Magna. Por un lado, existe una libertad de expresión, que no debería ser afectada, siempre y cuando no se infrinja la ley; y por otro lado, quien regula todas las posibilidades de enseñanza, no es el Obispo, sino el ministro del ramo, es decir, el Ministerio de Educación Pública, o las entidades competentes designadas para esta materia. Dicho de otro modo, la tesis de que una designación religiosa pueda restringir la libertad de cátedra es cuestionable desde el punto de vista del derecho costarricense, porque su restricción sería, en todo caso, relativa: estas directrices quedarían a criterio de las personas que dirijan y trabajen en ellas.

Para complementar lo anterior, puede ser de utilidad mencionar un caso histórico: la construcción de una capilla religiosa en el campus de la Universidad de Costa Rica. Aquí se trataba no ya de una universidad pontificia, que para entonces había sido derogada, sino de una universidad estatal, aconfesional. La siguiente argumentación es de Rodrigo Facio, para quien la edificación de un templo religioso en el campus universitario no debía significar un riesgo contra la autonomía docente y cultural, ni tampoco contra la libertad de cátedra:

Si se me demostrara que la existencia de una Capilla lleva implícita la destrucción de la autonomía universitaria, o algún peligro para la libertad de cátedra, o alguna lesión para la libertad, que la Constitución Política garantiza para todos los habitantes del país, de creer o no creer en Dios o de adorarlo cada uno a su modo; si se me demostrara cualquiera de esas cosas yo estaría naturalmente, y también por principio, contra la idea de la Capilla, porque como costarricense y como funcionario público 
estoy en la obligación de velar por el mantenimiento de los principios filosóficos y políticos en que se basa la Nación, y más profundamente porque, como hombre, estoy convencido - al margen de mis personales convicciones religiosas y políticas- de que en la libérrima discusión de todas las ideas descansa el progreso científico y la posibilidad de que todos los hombres sean respetados en su dignidad individual. (Romero Pérez, 2014, p. 27)

Aquí podría argumentarse algo similar a lo dicho anteriormente: la cultura de una organización podría verse influida por creencias religiosas. No obstante, y como se ha visto hasta el momento, la libertad de cátedra es un derecho asociado a la libertad de expresión; es decir, un derecho fundamental, como lo son el derecho a la vida y a la integridad física, el derecho a la libre objeción de conciencia y la libertad religiosa. En otras palabras, la existencia de creencias religiosas no debería suponer una extra limitación para el ejercicio de la libertad de cátedra sino, eventualmente, una restricción de carácter relativo.

Por restricción de carácter relativo puede entenderse que, si se abusara de la libertad de cátedra podría incurrirse en desórdenes institucionales, no solo de carácter académico, sino incluso administrativo. Un desorden de carácter académico se refiere a que la escogencia indiscriminada de temas y contenidos por parte del profesorado, así como el libre abordaje de estos, podría atentar contra la calidad académica y el orden curricular, puesto que un plan de estudios debería poseer una cierta coherencia y cadencia en los contenidos, así como pertinencia con el mercado. Un desorden de carácter administrativo, se refiere a que el profesorado debe atenerse a una responsabilidad laboral, que suele traducirse en una carga académica dentro de una unidad académica. El no respetar esa relación laboral podría afectar el proceso de aprendizaje del estudiantado, que tiene el derecho de recibir una educación de cierta calidad, previamente acordada con las autoridades competentes, ya sea la unidad académica a la cual pertenece el profesorado dentro de la universidad, o bien, la autoridad estatal que regula la educación superior.

Sobre este punto, podría ser un error por parte de la universidad ceder al profesorado la completa entrega de contenidos a sus estudiantes, porque de esta manera se podría desvirtuar el hecho educativo, facultando al profesorado para imponer su visión personal, su enfoque unilateral e incluso abusar del estudiantado en lo referente a su aprendizaje o sus derechos fundamentales. Gómez (2004) lo sintetiza de esta manera: 
No significa la libertad de cátedra de manera alguna que la universidad delega en el profesor toda la materia atinente a la organización y contenido de la materia objeto de enseñanza. Por el contrario, no es incompatible con dicha libertad la potestad de la universidad de poder definir el contenido y la programación de la cátedra correspondiente, incluida la definición de temarios para efectos de evaluación de los estudiantes. La libertad de cátedra no puede extrapolarse a tal punto que sea el profesor el que inclusive define el contenido del programa de estudios. (p. 83)

A propósito del riesgo que supone para la libertad de cátedra la injerencia del Estado, bastaría referirse a los casos mencionados de Alemania y España, y a lo mencionado por Gómez (2004, p. 86): "La autonomía le permite a la universidad la búsqueda de la verdad y ejercer la investigación científica, en tanto que la libertad de cátedra le garantiza a la propia universidad la creación y la transmisión crítica del saber". En Alemania, la libertad de cátedra es amplia; en España, la libertad de cátedra es relativa. En el caso de Costa Rica, puede encontrarse una mayor afinidad con la legislación y aplicación españolas, salvo que en Costa Rica este derecho se restringe a las instituciones de educación superior, mientras que en España, es más extenso.

Dicho esto, la relación entre libertad de cátedra e innovación educativa en la educación superior, debería resultar más sencilla de percibir. En el apartado anterior, se hizo referencia a los desafíos que la sociedad de la información imponía a las universidades tradicionales, usando como ejemplo de contraste las universidades en línea y las plataformas tecnológicas. En el presente apartado, se revisaron usos de la libertad de cátedra en contextos geográficos distintos, y se propuso que en cada país y en cada universidad variaba su aplicación. Llegados a este punto, es necesario vincular ambas realidades y hacer algunas afirmaciones: en primer lugar, la libertad de cátedra puede habilitar la innovación educativa, en la medida en que el profesorado universitario pueda hacer uso de distintas plataformas tecnológicas o nuevos recursos pedagógicos, haciendo esto compatible con la entrega de los contenidos y las obligaciones administrativas de carácter contractual.

En segundo lugar, la libertad de cátedra sí le permite al profesorado actuar de manera innovadora, en la medida en que logre impulsar sus habilidades intelectuales, conocimientos, estilo de pensamiento, personalidad, motivación y entorno (Schilling, 2016, p. 19). De esta manera, se pueden generar nuevas ideas, que sean útiles. En tercer lugar, gracias a la libertad de cátedra, la elaboración de un nuevo modelo pedagógico encuentra un medio 
apropiado para transferir el conocimiento, no solamente a sus estudiantes, sino también a la universidad, como una organización cuya cultura tradicional amerita ser transformada para bien. En definitiva, la libertad de cátedra permitirá no solo generar cambios en el proceso de enseñanza y aprendizaje de sus estudiantes, sino también amplificar y difundir las innovaciones educativas promovidas por el cuerpo docente a lo largo de la institución de educación superior.

\section{Conclusiones}

La historia de la humanidad y de la universidad han ido siempre de la mano, desde la Edad Media hasta la sociedad de la información y del conocimiento. Ambas han recorrido el sendero de la verdad, primero buscando la libertad, luego el libertinaje. La universidad debió innovar para enfrentar nuevos cambios de paradigma pedagógico, suscitados por nuevas tecnologías y oferentes en línea. Esto la obliga a innovar en sus estrategias didácticas incorporando plataformas de software y hardware. En este nuevo escenario, el profesorado universitario siguió siendo el principal agente de transformación.

La libertad de cátedra se concibe como un derecho que protege a las instituciones de la imposición de ideologías externas, especialmente las gubernamentales, para que el poder del Estado no conculque la autoridad de la universidad. Este mismo derecho lo puede aplicar el profesorado en las aulas, impidiendo que sea la misma institución universitaria la que lo obligue a enseñar doctrinas particulares. La legislación de la libertad de cátedra es asumida desde diferentes perspectivas en cada país. En España, no hace explícita la posibilidad del profesor para utilizar metodologías específicas, sino que se limita a la libertad ideológica del profesorado para abordar los contenidos. En Alemania hace referencia a la libertad pedagógica, e impide que instancias civiles e institucionales intervengan en el libre desempeño del profesorado.

De esto se puede suponer que la contraposición de la libertad de cátedra con respecto a un profesor que innova dentro de su universidad exige un análisis jurídico para cada país, a fin de comprender los alcances que la legislación tiene en cada Estado. Dicho de otro modo, según la legislación de cada país o la normativa institucional, el profesorado estará en capacidad de desacatar a su universidad "de hecho", pero no de derecho, en caso de no ser una cuestión sumamente vinculante.

En cuanto a la libertad de cátedra costarricense, se puede concluir que es un habilitador de la innovación educativa por parte del profesorado, en la medida en que decida 
utilizar métodos, contenidos o procesos de enseñanza novedosos -lo que antes se definió como libertad pedagógica-, de suerte que la institución que esté poco abierta al cambio, podría innovar de manera paulatina, según la iniciativa de su profesorado.

Por otra parte, cuando el profesorado universitario decide impulsar la innovación, tendrán a su vez la posibilidad de promover un cambio cultural en toda la organización, de suerte que se difunda entre el estudiantado y, por consiguiente, la institución que esté poco anuente a innovar se vea obligada a hacerlo, y el profesorado que esté dispuesto a innovarse vea confirmado en sus motivaciones. Por tanto, la libertad de cátedra en Costa Rica habilitará los procesos de innovación en el ámbito de la educación superior de manera relativa.

\section{Referencias}

Christensen, Clayton; Johnson, Curtis W.; and Horn, Michael B. (2008). Disrupting Class: How Disruptive Innovation Will Change the Way the World Learns [El aula disruptiva: cómo la disrupción cambiará el modo en que el mundo aprende]. New York: McGrawHill.

Eyring, Henry;and Christensen, Clayton. (2011). Changing the DNA of Higher Education. Washington DC: American Council on Education.

Foucault, Michel. (1992). Microfísica del poder [Varela, Julia y Álvarez-Uría, Fernando Trad.]. Madrid: La Piqueta.

Gómez, Celín. (2004). La libertad de cátedra. Revista de Ciencias Jurídicas, (104). 71-90.

González-del-Valle, José M. (1981). Libertad de cátedra y libertad de enseñanza en la legislación española. Persona y Derecho, 8, 314-327.

Herrero López, Montserrat. (2015). Poder, gobierno, autoridad: la condición saludable de la vida política. Madrid: Centro de Estudios Políticos y Constitucionales.

Llano, Alejandro. (2012). La universidad y el tiempo. En Alma mater (pp. 91-108). Perú: Universidad Católica Santo Toribio de Mogrovejo.

Madrid, Raúl. (2013). El derecho a la libertad de cátedra y el concepto de universidad. Revista Chilena de Derecho, 40(1), 353-369.

Malagón, Roberto Suárez. (2011). Contenido y límites de la libertad de Cátedra en la enseñanza pública no universitaria. Revista de Derecho UNED, (9), 421-462.

Romero Pérez, Jorge. (2014). Rodrigo Facio Brenes (1917-1961): anotaciones de su perfil personal. Revista de Ciencias Sociales, (138), 21-40. 
Schilling, Melissa A. (2016). Strategic Management of Technological Innovation. New York: McGraw Hill Education.

Sistema Costarricense de Información Jurídica. (1949). Constitución Política de la Republica de Costa Rica. Recuperado de http://www.pgrweb.go.cr/scij/busqueda/normativa/normas/nrm_texto_completo.aspx?par am1=NRTC\&nValor1=1\&nValor2=871\&strTipM=TC

Tidd, Joe; Bessant, John; and Pavitt, Keith. (2005). Managing Innovation: Integrating Technological, Market and Organizational Change (3rd ed.). England: John Wiley \& Sons Ltd.

Vidal, Carlos. (2004). Libertad de cátedra y libertad pedagógica en Alemania. Persona y Derecho, (50), 373-409. 
Revista indizada en
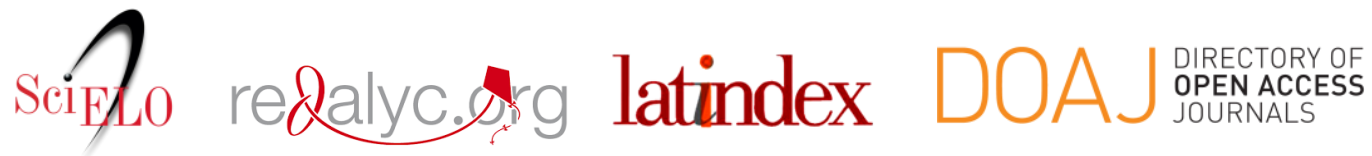

Distribuida en las bases de datos:

- Dialnet

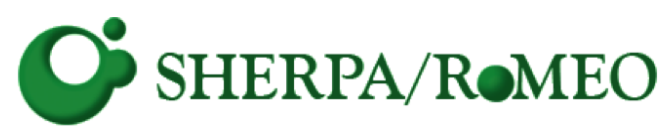

REDIB

Red Iberoamericana

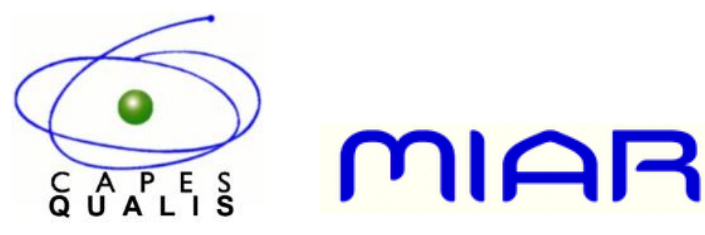

